УДК 304.44

DOI: 10.18101/1994-0866-2020-2-61-67

\title{
ИНФОРМАЦИОННЫЕ КАНАЛЫ В МОБИЛЬНЫХ МЕССЕНДЖЕРАХ: ФИЛОСОФСКИЙ АНАЛИЗ
}

\author{
(C) Гунзынов Жаргал Паламович \\ преподаватель, \\ Бурятский государственный университет им. Доржи Банзарова \\ Россия, 670000, г. Улан-Удэ, ул. Смолина, 24а \\ E-mail: gzzrl@yandex.ru
}

Информационные каналы стали новым явлением в российском медиапространстве. Популярные в мире и в России мессенджеры используются абонентами не только для общения, но и как источник новостей.

В представленной статье автором осуществляется попытка провести анализ природы информационных каналов в социальных мессенджерах на основе диалектического, синергетического подходов. Автор ставит перед собой задачу определить общие закономерности появления феномена подобных информационных каналов на примере телеграм-каналов, а также ответить на вопрос, являются ли они новой формой средств массовой информации. В основе исследования лежит анализ научно-философских подходов к изучению средств массовой информации, а в случае с неоднозначным правовым статусом Telegram - также обращение к действующему законодательству Российской Федерации.

Ключевые слова: средства массовой информации; мессенждеры; диалектический подход; Telegram.

\section{Для цитирования}

Гунзынов Ж. П. Информационные каналы в мобильных мессенджерах: философский анализ // Вестник Бурятского государственного университета. Философия. 2020.

Вып. 2. С. 61-67.

Информационные потоки в современном обществе чрезвычайно многообразны и стремительно развиваются. В последнее время в мировом медиапространстве появился новый феномен - информационные каналы в мобильных мессенджерах. Этот вид распространения массовой информации продолжает набирать все большую популярность, уже конкурируя с угасающими печатными СМИ и телевидением, а также вплотную подбираясь по количеству ежедневной аудитории к интернет-СМИ. Таким образом, информационные каналы в мобильных мессенджерах становятся в том числе объектом научных исследований. Отсюда возникает необходимость разработки методологических основ таких исследований.

Безусловно, мобильные мессенджеры и их информационные каналы как феномены объективной действительности могут быть рассмотрены с самых разных аспектов. В настоящем исследовании мы ставим целью выявление природы и специфики информационных каналов на примере мессенджера Telegram как средства массовой информации, чтобы тем самым найти подтверждение гипотезе о появлении массмедиа нового формата. 
Ж. П. Гунзынов. Информационные каналы в мобильных мессенджерах: философский анализ

В настоящем исследовании особое внимание будет уделено информационным каналам в мессенджере Telegram, так как, по нашему мнению, он имеет свои особенности как по функционалу, так и по своему правовому статусу.

Правовой статус Telegram в России на сегодняшний день остается неопределенным. С одной стороны, действует судебный запрет на функционирование этого мессенджера на территории страны. Но технически этот запрет реализовать не удалось ${ }^{1}$. Telegram остается доступен для свободного скачивания и использования в России. Более того, в октябре 2019 г. замминистра цифрового развития, связи и массовых коммуникаций Российской Федерации Алексей Волин заявил, что использование абонентами Telegram не запрещено: «...одно другому не противоречит. Решение о блокировке сервиса технического не означает запрет на пользование этим сервисом» ${ }^{2}$. Что в целом соответствует сложившейся действительности. Telegram занимает третье место по популярности среди абонентов российских мобильных сетей, уступая только мессенджерам WhatsApp и Viber ${ }^{3}$. В то же время он имеет ряд функциональных отличий.

Информационные каналы в Telegram представляют из себя группы абонентов, в которых возможно опубликование информации в виде ленты новостей. Особенностью таких групп является анонимность как автора публикации, так и администраторов группы, а также анонимность самих участников группы друг для друга. В открытом доступе остается только информация об общем количестве подписчиков информационного канала.

Именно такая анонимность в публикации новостей, а также абсолютная закрытость переписки абонентов, в том числе и для самой администрации мессенджера, стали основанием для блокировки Telegram на территории России по решению суда. Но такая блокировка не была осуществлена по техническим причинам, на сегодняшний день мессенджер Telegram по-прежнему находится в свободном доступе на территории России и остается одним из самых популярных.

Рассуждения о методологии исследований нужно начинать, отталкиваясь от специфики объекта исследования. Здесь мы сразу сталкиваемся с двойственным характером телеграм-каналов. Мы видим одновременный запрет и большую популярность, что наталкивает на мысль о наличии признака, присущего, в целом, бытию - единства и борьбы противоположностей. Как отмечал в конспектах «К вопросу о диалектике» В. И. Ленин, «условие познания всех процессов мира в их самодвижении, в их спонтанном развитии, в их живой жизни, есть познание их, как единства противоположностей» [1]. Поэтому в исследовании природы информационных телеграм-каналов нельзя обойтись без диалектического подхода. На примере СМИ это можно увидеть во взаимодействии самих средств массовой информации (их редакций, отдельных журналистов) и их аудитории.

\footnotetext{
1 Верховный суд отклонил жалобу Telegram по делу о блокировке. URL: https:// www.kommersant.ru/doc/3872889 (дата обращения: 03.05.2020).

2 Минкомсвязь назвала законным использование Telegram в России // РБК. URL: https://www.rbc.ru/technology_and_media/24/10/2019/5db140a99a79471440318a18 (дата обращения: 03.05.2020).

${ }^{3}$ Исследование аудитории Телеграм. URL: https://tgstat.ru/research (дата обращения: 10.01.2020).
} 
Размышляя диалектически, можно выявить следующую особенность средств массовой информации. Существует множество определений того, что следует понимать под СМИ. Но их смысл заложен уже в самом термине. Мы видим здесь слияние понятий «средство» и «массовая информация». Под средством можно понимать, в частности, «прием, способ действий для достижения чего-нибудь» [2]. Критерием массовости информации можно назвать публичный характер, ее открытость, доступность и направленность на неограниченный круг лиц. По смыслу то же самое содержится, например, в Законе РФ «О средствах массовой информации». Так, согласно ст. 2 Закона РФ «О средствах массовой информации», под массовой информацией понимаются предназначенные для неограниченного круга лиц печатные, аудио-, аудиовизуальные и иные сообщения и материалы ${ }^{1}$.

Таким образом, диалектический подход к природе СМИ можно применить следующим образом. «Тезис» - способ передачи, распространения массовой информации; «антитезис» или противопоставление ему — это аудитория, т.е. конечные получатели или потребители массовой информации. Очевидно, что без аудитории ни одно средство передачи информации, нельзя назвать СМИ, как и аудитория, не получая массовую информацию, не может именоваться аудиторией именно массмедиа. Таковы существенные признаки обоих объектов.

Выявив два элемента, противопоставленные друг другу, нужно выявить третий элемент, осуществив так называемое «снятие». Сам Гегель говорил о снятии, что оно «проявляет свое подлинное двойное значение, которое мы видели в негативном: оно есть процесс негации и в то же время сохранение; ничто как ничто "этого", сохраняет непосредственность, оно даже чувственно, но есть непосредственность всеобщая» [3]. Снятие в случае со СМИ проявляется в самом восприятии аудиторией информации и, наоборот, в стремлении журналистов распространять именно ту информацию, которая интересна ее получателям.

Соответственно можно вывести и «синтезис», который, по нашему мнению, формулируется следующим образом: средство массовой информации - это единство средства передачи информации и неограниченного круга получателей информации. Продолжая размышление, можно утверждать, что массовая информация становится массовой только проходя через сознание неограниченной аудитории, в то же время неограниченная аудитория СМИ может считаться таковой, если круг лиц, входящих в нее, невозможно четко ограничить.

Безусловно, такое умозаключение весьма кратко, но уже содержит два основных, на наш взгляд, признака массмедиа: определенный способ передачи информации, обеспечивающий доступ к ней неограниченному кругу лиц, и наличие этой самой неограниченной аудитории, которая на постоянной основе потребляет такую информацию.

Стоит добавить, что информационные каналы по своей сути являются олицетворением новых СМИ, феномен которых уже становился объектом изучения

${ }^{1}$ О средствах массовой информации: закон РФ от 27.12.1991 № 2124-1. Доступ из справочно-правовой системы КонсультантПлюс. URL: http://www.consultant.ru/docu-ment/ cons_doc_LAW_1511/f977773d5130bdc4b8aa5c541d1fa7ca381b18f4/ (дата обращения: 28.04.2020). 
Ж. П. Гунзынов. Информационные каналы в мобильных мессенджерах: философский анализ

многих исследователей. В частности, Э. Тоффлером в 1990 г. было предсказано появление средств массовой информации «третьей волны». К их признакам он относил, в частности, демассификацию [4]. Такая демассификация возможна путем придания интерактивного характера информации, т. е. пользователи могут сами определять тематику новостей, с которыми они хотят знакомиться, отсекая лишнюю информацию. В случае с информационными каналами в мобильных мессенджерах это достигается путем подписки на них, исходя из их тематического направления.

Еще одним признаком новых СМИ, по Тоффлеру, следует назвать мобильность. Мобильность позволяет получать информацию, находясь в самых разных местах благодаря использованию мобильных телефонов и планшетов. Если печатные издания позволяли получать информацию в зависимости от периодичности их выхода (самое частое - раз в день), телевидение обеспечивало поступление новостей с периодичностью раз в несколько часов, то развитие сети Интернет позволило освещать события фактически в реальном времени. При этом мессенджеры еще и позволяют делать это в пассивной форме: человеку не нужно самому делать поисковые запросы, информационные каналы сами присылают ему новости на интересующие его темы. Таковы уникальные черты информационных групп в мобильных мессенджерах, если на них взглянуть через призму диалектического подхода.

Таким образом, можно сделать вывод, что телеграм-каналы как частный пример информационных каналов в мобильных мессенджерах являются средством массовой информации, причем совершенно новым «средством».

Продолжая анализ природы информационных каналов в мобильных мессенджерах, нельзя обойти стороной возможности использования основных принципов диалектического подхода.

Диалектика взаимодействия СМИ и общественного мнения проявляется в деятельности в самых различных аспектах, например в единстве и борьбе переходящих друг в друга материального и идеального, объективного и субъективного в следующей форме:

- любое событие можно определить как материальное, происходящее в объективной действительности. Например, превышение должностными лицами своих полномочий, дорожно-транспортное происшествие и т. д.;

- журналист, пишущий об этом событии новость, переводит его в идеальное состояние, т. е. превращает его в информацию, выраженную в виде текста. И наоборот, под влиянием новостей (например, негативного характера) формируется критическое общественное мнение, которое иногда даже может привести к массовым акциям протеста. Примером этого могут стать протестные митинги в г. Улан-Удэ, произошедшие в сентябре 2019 г. Тогда немалую роль в их освещении, в формировании повестки и привлечении граждан к участию в митингах сыграли паблики в социальных сетях и информационные каналы в мессенджерах. Причем анонимность именно телеграм-каналов позволила распространять такой контент, который блокировался на других ресурсах.

Само появление информационных каналов в мобильных мессенджерах стало возможным благодаря поиску новых способов распространения информации. Очевидно, что появление и развитие Интернета уже сейчас фактически разрушило 
рынок печатных газет и журналов, тиражи которых, за редким исключением, значительно упали. То же самое можно сказать и про телевидение, которое все больше ориентируется на вещание в сети Интернет. Практически все ведущие телевизионные каналы в России имеют собственные аккаунты в социальных сетях и на видеохостинге Youtube, где выкладывают интернет-версии своих телепередач.

Следующим этапом стало уже развитие самих интернет-СМИ. Ведущие информационные агентства создали свои новостные сайты (в Бурятии, например, infpol.ru, baikal-daily.ru и др.). Популярность такого формата привело к увеличению количества новостных сайтов, что спровоцировало поиск новых конкурентных преимуществ. Это привело сначала к созданию пабликов в социальных сетях, а затем и к перепрофилированию на работу в мобильных мессенджерах многих журналистов, что требует иного стиля написания и подготовки новостных материалов, нежели в прежних форматах СМИ.

Здесь мы, очевидно, сталкиваемся и с результатом конкуренции на рынке медиауслуг. Предложение в какой-то момент стало явно превышать спрос на информацию среди аудитории. Известны примеры информационных агентств, которые вели свою деятельность в сети Интернет, но в итоге закрылись из-за финансовых проблем (например, Ulanmedia.ru).

Приведенное выше описание в общих чертах демонстрирует развитие российского медиапространства и, в частности, медиапространства Республики Бурятия. Это подтверждается, например, статистическими данными.

Так, в Республике Бурятия наиболее популярными новостными телеграм-каналами являются каналы «Ньюбур» и «Степной дозор». Согласно данным агентства «Telegram Analytics», у «Степного дозора» по состоянию на 15 мая 2020 г. насчитывается 9922 подписчиков, у «Ньюбур» - 4607 подписчиков ${ }^{1}$. Однако подписчиков можно назвать постоянной аудиторией каналов, тогда как просмотр их содержания возможен и без подписки. Поэтому интересны будут и данные по количеству ежедневных просмотров публикаций.

По данным того же агентства «Telegram Analytics», среднее число просмотров новостей за день для канала «Степной дозор» превышает 72 тысячи, для «Ньюбур» более 52 тысяч посетителей в день. Эти цифры уже сопоставимы, а иногда и превышают аналогичную статистику по ведущим новостным сайтам Бурятии. Например, на протяжении последних лет абсолютным лидером по посещениям является сайт информационного агентства «Байкал-Дейли». Согласно статистическим данным агентства Mail.ru среднее количество ежедневных посетителей сайта этого интернетпортала по состоянию на май 2020 года составляет около 70 тысяч ${ }^{2}$.

Специфику информационных каналов в мобильных мессенджерах как средств СМИ составляют, по нашему мнению, следующие элементы:

1. Особый способ распространения информации (через смартфоны в форме сообщений в мессенджерах).

1 Телеграм-каналы России. URL: https://tgstat.ru/research (дата обращения: 15.05.2020).

2 Рейтинг СМИ. Онлайновые издания. URL: https://top.mail.ru/Rating/MassMediaOnline/Month/Hits/ (дата обращения: 15.05.2020). 
Ж. П. Гунзынов. Информационные каналы в мобильных мессенджерах: философский анализ

2. Особая форма связи между источником, посредником и получателем информации (кто фактически является источником и посредником, зачастую остается неизвестным для аудитории в силу анонимности, которая обеспечивается функционалом мессенджеров).

Анонимность публикаций не позволяет установить авторство публикаций, что может негативно проявиться, в частности, в вопросах привлечения к ответственности авторов за распространение заведомо недостоверной информации, порочащей честь и достоинство, деловую репутацию; за злоупотребление правами журналистов и свободой слова, за оскорбления в публичной среде и т. д.

В целом увеличение количества информационных каналов как нового вида массмедиа приводит к появлению новых форм распространения массовой информации. Администраторами практически всех телеграм-каналов Бурятии являются журналисты, ранее работавшие в интернет-СМИ. Это, например, Евгения Балтатарова и ее телеграм-канал baltatarova, Аркадий Зарубин, который, по информации тех же телеграм-каналов, является администратором «Степного дозора». В такой профессиональной переквалификации очевидно прослеживается преемственность между сетевыми изданиями и пабликами в мессенджерах.

Вполне очевидным становится и проявление диалектичского закона отрицания отрицания. Новые тенденции в развитии технологий постепенно приводят к снижению популярности старых форм СМИ. В настоящее время мы становимся свидетелями угасания печатных средств массовой информации, спровоцированного сначала распространением телевидения, а затем сети Интернет. В свою очередь, Интернет стал выигрывать конкуренцию у телевидения, а затем и информационные каналы в мобильных мессенджерах стали занимать свою нишу.

Очевидно, что каждый раз, когда мы говорим о снижении востребованности одной формы СМИ и роста популярности другой, мы понимаем уменьшение интереса аудитории СМИ к одной форме и увеличение к другой. То есть внимание людей переключается с одного способа получения информации на другой.

Таким образом, появление информационных каналов в мобильных мессенджерах обусловлено с позиции диалектики самим развитием общественных процессов и сменой устаревших форм более новыми. В будущем можно ожидать появление еще более новых форм массмедиа, которые придут на смену информационным каналам в мессенджерах и переключат внимание аудитории на себя.

Опираясь на синергетический подход и на парадигму сложностности, которую В. И. Аршинов называет новым этапом в развитии синергетической теории, отметим, что информационные каналы в мобильных мессенджерах есть органичная часть интерактивного процесса конструирования реальности. При данном типе массовой коммуникации и передачи информации стороны имеют расширенные возможности комментировать, оценивать, «репостить» и т. д.

Сложность, отмечает В. И. Аршинов, становится источником порождения новых качеств [11]. Добавим также, что современное информационное интернет-пространство характеризуется процессами дробления, разветвления, увеличения многообразия каналов, информационных продуктов. Все это порождает максимум «неопределенности», которая также есть один из тех феноменов, требующих для своего изучения междисциплинарного подхода, в который можно включить теорию самоорганизации или синергетику [5]. Развитие современного медиапространства можно характеризовать как единство хаотических тенденций (когда возникает множество разнообразных 
каналов, транслирующих разнородные ценности, полярные смыслы) и процесса конвергенции, придающих устойчивость и стабильность.

Природа информационных каналов в мессенджерах вполне очевидна. На сегодняшний день они стали новой формой массмедиа, предлагающей качественно иной способ распространения массовой информации, пользующийся большой популярностью у пользователей мобильных мессенджеров. Их специфика требует дополнительного изучения, в том числе для разработки эффективного механизма правового регулирования, технических способов контроля их деятельности, а также наиболее эффективных методов использования популярности телеграм-каналов для реализации социально полезных проектов и различных направлений государственной политики.

\section{Лuтература}

1. Гегель Ф. Наука логики. Текст: электронный. URL: https://web.archive.org/web/20111026195238/http://www.philosophy.ru/library/hegel/01/wahrnehm.html\# (дата обращения: 11.01.2020).

2. Ушаков Д. Н. Толковый словарь Ушакова. Текст: электронный. URL: https://dic.academic.ru/dic.nsf/ushakov/1040150 (дата обращения: 28.04.2020).

3. Гегель Ф. Феноменология духа. Текст: электронный. URL: https://web.archive.org/web/20111026195238/http://www.philosophy.ru/library/hegel/01/wahrnehm.html\# (дата обращения: 04.05.2020).

4. Тоффлер Э. Третья волна. М.: ACT, 2004. Текст: электронный. URL: http://www.umk.virmk.ru/study/VMK/LITERA/Toffler_Tretiya_volna.pdf (дата обращения: 04.05.2020).

5. Фролова М. И. Мир человека: неопределенность как вызов (17-е Фроловские чтения) // Вопросы философии. 2018. № 4. Текст: электронный. URL: http://vphil.ru/index. php?option=com_content\&task=view\&id=1936\&Itemid=52 (дата обращения: 20.05.2020).

\section{INFORMATION CHANNELS IN MOBILE MESSENGERS:}

\section{A PHILOSOPHICAL ANALYSIS}

\section{Zhargal P. Gunzynov}

Lecturer,

Dorzhi Banzarov Buryat State University

24a Smolina St., Ulan-Ude 670000, Russia

E-mail: gzzrl@yandex.ru

Information channels have become a new phenomenon in the Russian media scene. Subscribers use popular in the world and Russia messengers not only as a way of communication, but also as news sources.

The article attempts to analyze the nature of information channels in social messengers based on dialectic and synergetic approaches. We set us the task to determine the common factors of the development of such phenomena as information channels using Telegram channels as an example, and also to identify whether they are a new form of mass media. The study is based on the analysis of scientific and philosophical approaches to the media. In the case of ambiguous legal statuses of Telegram, we also invoke the current legislation of the Russian Federation.

Keywords: mass media; messengers; dialectic approach; Telegram. 